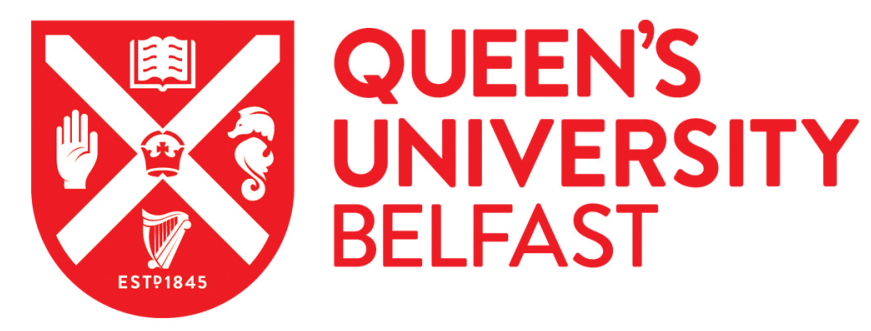

\title{
In vitro differential responses of rat and human aryl hydrocarbon receptor to two distinct ligands and to different polyphenols
}

Doan, T. Q., Connolly, L., Igout, A., Muller, M., \& Scippo, M. L. (2020). In vitro differential responses of rat and human aryl hydrocarbon receptor to two distinct ligands and to different polyphenols. Environmental pollution (Barking, Essex : 1987), 265(Pt B), 114966. https://doi.org/10.1016/j.envpol.2020.114966

Published in:

Environmental pollution (Barking, Essex : 1987)

Document Version:

Peer reviewed version

Queen's University Belfast - Research Portal:

Link to publication record in Queen's University Belfast Research Portal

Publisher rights

Copyright 2020 Elsevier.

This manuscript is distributed under a Creative Commons Attribution-NonCommercial-NoDerivs License

(https://creativecommons.org/licenses/by-nc-nd/4.0/), which permits distribution and reproduction for non-commercial purposes, provided the author and source are cited

\section{General rights}

Copyright for the publications made accessible via the Queen's University Belfast Research Portal is retained by the author(s) and / or other copyright owners and it is a condition of accessing these publications that users recognise and abide by the legal requirements associated with these rights.

Take down policy

The Research Portal is Queen's institutional repository that provides access to Queen's research output. Every effort has been made to ensure that content in the Research Portal does not infringe any person's rights, or applicable UK laws. If you discover content in the Research Portal that you believe breaches copyright or violates any law, please contact openaccess@qub.ac.uk. 


\section{In vitro differential responses of rat and human aryl hydrocarbon receptor to}

\section{2 two distinct ligands and to different polyphenols}

3 Doan $\mathrm{TQ}^{1}$, Connolly $\mathrm{L}^{2}$, Igout $\mathrm{A}^{3}$, Muller $\mathrm{M}^{4}$, Scippo $\mathrm{ML}^{1 *}$

4 'Laboratory of Food Analysis, FARAH-Veterinary Public Health, University of Liège, Liège,

5 Belgium, 4000;

6 'Institute for Global Food Security, School of Biological Sciences, Queen's University Belfast,

7 Northern Ireland, UK, BT9 5DL;

8 3Department of biomedical and preclinical sciences, Faculty of Medicine, University of Liège,

9 Liège, Belgium, 4000;

$10{ }^{4}$ GIGA-R, Laboratory for Organogenesis and Regeneration, University of Liège, Liège,

11 Belgium, 4000;

12 “Corresponding author Scippo ML: mlscippo@uliege.be

13 Muller M and Scippo ML equally contributed as the last authors.

Abstract

TCDD (2,3,7,8-tetrachlorodibenzo-p-dioxin) and several other environment/food-borne toxic compounds induce their toxicity via the aryl hydrocarbon receptor (AhR). AhR is also modulated by various endogenous ligands e.g. highly potent tryptophan (Trp)-derivative FICZ (6-formylindolo[3,2-b]carbazole) and natural ligands abundant in the human diet e.g. polyphenols. Therefore, evaluating AhR species-specific responses is crucial for understanding AhR physiological functions, establishing risk assessments, and exploring the applicability of AhR mediators in drug and food industry towards human-based usages. We studied AhR transactivation of FICZ/TCDD in vitro in a time-dependent and species-specific manner using dioxin responsive luciferase reporter gene assays derived from rat (DR-H4IIE) and human (DR-HepG2) hepatoma cells. We observed for the first time that FICZ potency was similar in both cell lines and was 40 times higher than TCDD in DR-HepG2 cells. Depleting 
27 Trp-derivative endogenously produced ligands by using culture medium without Trp, resulted 28 in 3-fold higher AhR activation upon adding FICZ in DR-H4IIE cells, in contrast to DR-HepG2 29 cells which revealed a fast degradation of FICZ induction from 10h post-exposure to complete 30 disappearance after $24 \mathrm{~h}$. Seven polyphenols and a mixture thereof, chosen based on 31 commercially recommended doses and adjusted to human realistic exposure, caused rat and human species-specific AhR responses. Two isoflavones (daidzein and genistein) induced rat 33 AhR synergistic effects with FICZ and/or TCDD, while quercetin, chrysin, curcumin, 34 resveratrol, and the mixture exerted a strong inhibitory effect on the human AhR. Strikingly, resveratrol and quercetin at their realistic nanomolar concentrations acted additively in the mixture to abolish human AhR activation induced by various TCDD concentrations. Taken

37 together, these results illustrate the species-specific complexity of AhR transcriptional activities modulated by various ligands and highlight the need for studies of human-based approaches.

40 Keywords: Aryl hydrocarbon Receptor; Rat versus Human; Polyphenols; H4IIE cells; HepG2 41 cells

43 Capsule: Diet-borne endogenous and exogenous AhR modulators act differentially in human and rat hepatoma cells with quercetin and resveratrol being strong human AhR antagonists. 


\section{Introduction}

48 The aryl hydrocarbon receptor $(\mathrm{AhR})$ is known for its role as a xenobiotic mediator (Hankinson, 1995). Environment/food-borne contaminants like 2,3,7,8-tetrachlorodibenzo-p-dioxin (TCDD) induce their toxicity via the AhR signaling pathway (Kawajiri and Fujii-KuriYama, 2016). Ligand (TCDD)-activated AhR undergoes a translocation from the cytosol to the nucleus to partner with the aryl hydrocarbon receptor nuclear translocator (ARNT). This AhR/ARNT heterodimer then binds to DNA sequences called dioxin responsive elements (DREs) to activate the expression of AhR inducible genes, including the cytochrome p450 (CYP) family (e.g. CYP1A1) belonging to the phase I drug-metabolizing enzymes. In addition to the AhR canonical pathway as described above, the AhR noncanonical pathway regulates the expression of genes lacking DREs by binding as a heterodimer with novel partners e.g. RelB or Krüppel-like Factor 6 via a site distinct from the consensus DREs, or importantly, via crosstalks with other signaling pathways (Wright et al., 2017). Nevertheless, the methods measuring DRE-regulated gene expression are widely accepted for determining AhR activation (Wall et al., 2015), among which cell-based screening methods such as luciferase reporter gene assays are amongst the most common (Scippo et al., 2004).

AhR is also activated by a wide range of endogenous and natural ligands to regulate several vital physiological functions in development and homeostasis, including immune responses, cell differentiation and proliferation, reproduction, and tumor suppression (Fujii-Kuriyama and Kawajiri, 2010). Indeed, AhR is considered as a sensor, connecting external environmental signals to cellular processes (Fujii-Kuriyama and Kawajiri, 2010; Marlowe and Puga, 2005). AhR functions can be dysregulated by inappropriate ligand-induced activation or inhibition, leading to subsequent health concerns (Marlowe and Puga, 2005; Xue et al., 2017).

Catabolism of the essential amino acid tryptophan (Trp) either by the host or by the symbiotic microbiota yields numerous physiologically relevant AhR ligands (Hubbard et al., 2015; Stejskalova et al., 2011). Among them, 6-formylindolo[3,2-b]carbazole (FICZ) is considered 
the highest affinity AhR ligand to date with an estimated dissociation constant $\mathrm{K}_{d}$ of $0.07 \mathrm{nM}$, which is significantly lower than the TCDD $\mathrm{K}_{d}$ of $0.48 \mathrm{nM}$, measured in a competitive binding assay performed in rat hepatic cytosol (Rannug et al., 1987). FICZ is produced by photochemical reactions under ultraviolet and visible light (Fritsche et al., 2007; Wincent et al., 2009) or by enzymatic and oxidative pathways (Smirnova et al., 2016; Wincent et al., 2009), likely resulting in a systemic distribution of FICZ (Smirnova et al., 2016) to perform several essential functions especially in immunity (Rannug and Rannug, 2018). FICZ is able to activate AhR in various species such as fish (Jönsson et al., 2009), frog (Laub et al., 2010), and birds (Farmahin et al., 2014; Kim et al., 2016). However, little is known about its potency and mode of action compared to the widely studied AhR ligand TCDD.

On the other hand, polyphenols represent the largest source of AhR natural modulators in the human diet (Xue et al., 2017). They are secondary metabolites of plants with a common polyphenol structure and diverse chemical entities (Quideau et al., 2011). They are popular in research and food manufacture due to their significant antioxidant ability which could be useful to prevent various diseases associated with oxidative stress e.g. cancer, cardiovascular, and neurodegenerative diseases (Hardman, 2014; Karunaweera et al., 2015). Besides, they are also able to modulate the activity of several enzymes and receptors (Middleton et al., 2000). For example, polyphenols have been shown to affect AhR activities in several ways including directly as AhR functional agonists or antagonists, indirectly by interfering with AhR translocation, AhR-ARNT heterodimerization, AhR-DNA binding, or altering AhR co-activators and co-repressors (Xue et al., 2017).

While most risk assessment data for humans are based on rodent models, there are large interspecies differences in susceptibility to toxic effects induced by dioxins (Moriguchi et al., 2003), and potentially by these endogenous and natural AhR ligands. Therefore, evaluating AhR responses depending on species exposed is crucial to understanding the physiological 
102 functions of this receptor, to establish risk assessment, and to apply AhR endogenous and

103 natural mediators in drug and food industry towards human-based usages.

105 In this study, luciferase reporter gene cell-based assays involving rat and human hepatoma cells were applied to study the effect of FICZ versus TCDD and commonly commercialized polyphenols on AhR species-specific responses. Rat H4IIE and human HepG2 cells were used as species representatives since they contain the respective species-specific AhR along

109 with the direct regulators of the AhR signaling pathways such as ARNT or co-factors, 110 regardless of their cancerous cellular machinery. Moreover, while TCDD-elicited gene 111 expression in rat H4IIE cells is consistent with in vivo rat studies (Dere et al., 2011), human

112 HepG2 cells are considered amongst the best single-cell models described for predicting 113 human toxicity (O'Brien, 2014), especially involving CYP1A1/2 activities (Choi et al., 2004).

114 The aims of the present study were to: (a) investigate AhR species-specific (rat versus human) 115 responses to FICZ and TCDD in the presence or absence of endogenous ligands by 116 comparing medium with Trp and without Trp-the major source of AhR endogenous ligands,

117 (b) evaluate effects of polyphenols and a mixture thereof, either alone or co-exposed with 118 FICZ or TCDD to mimic realistic exposure to mixtures of AhR modulators, and (c) reveal the 119 most active polyphenol(s) and possible interactions among these compounds in the mixture.

\section{2. Materials and methods}

\section{2.1. Chemicals and suppliers}

123 FICZ was bought from Sigma Aldrich (Missouri, USA), while TCDD was obtained from 124 Wellington Laboratories (Ontario, Canada). Seven polyphenols: daidzein, quercetin, 125 resveratrol, genistein, baicalin, curcumin, and chrysin were selected based on their commonly 126 commercial availability as food supplements. They were purchased from Sigma Aldrich and 127 dissolved in dimethylsulfoxide (DMSO) (Acros Organics, Molinons, France). Their detailed 128 description is given in Table S1. A mixture of these seven polyphenols was designed to reflect 
129 the realistic mixture exposure scenario of humans based on food supplement consumption or

130 via their diet. The mixture contained each polyphenol at a concentration corresponding to a

131 theoretical blood level arbitrarily calculated considering that the recommended ingested dose

132 is diluted in five liters of blood, with an additional 1000 -fold dilution factor to consider the

133 intestinal absorption and the high metabolic rate of polyphenols. The nanomolar

134 concentrations of the polyphenols in the mixture at blood level (Table S1) were relevant to

135 human exposure (Williamson, 2017). The stock solutions and working solutions of the

136 polyphenols and the mixture were stored at $-20^{\circ} \mathrm{C}$ and protected from light. Six successive 2-

137 fold dilutions were prepared freshly from the stock solution to obtain the tested concentrations

138 which did not exceed $50 \mu \mathrm{M}$ for the polyphenols and $65 \mu \mathrm{M}$ for the mixture.

140 2.2. Determination of aryl hydrocarbon receptor transcriptional activities

$141 \quad$ 2.2.1. Cell lines and luciferase reporter gene cell-based assays

142 Two dioxin responsive (DR) hepatoma cell lines were used, rat DR-H4IIE from BioDetection

143 System (Amsterdam, The Netherlands) (DR-CALUX ${ }^{\circledR}$ ) and human DR-HepG2 previously

144 produced within the laboratory of Prof. Scippo (Liege, Belgium) (Van der Heiden et al., 2009).

145 These cells were stably transformed with a vector containing four DREs, either from the mouse

146 Cyp1a1 promotor for DR-H4IIE cells or synthetic for DR-HepG2 cells, upstream of, 147 respectively the mouse mammary tumor virus promoter (Garrison et al., 1996) or the thymidine 148 kinase promoter (Van der Heiden et al., 2009) which control the transcription of a luciferase 149 reporter gene. The cells were cultivated in MEM $\alpha$ (Thermo Fisher Scientific, Massachusetts, 150 USA) with $10 \% \mathrm{v} / \mathrm{v}$ fetal bovine serum (Greiner, Kremsmünster, Austria) and $50 \mathrm{IU} / \mathrm{mL}$ 151 penicillin and $50 \mu \mathrm{g} / \mathrm{mL}$ streptomycin (Sigma Aldrich), and were maintained in a water saturated atmosphere containing $5 \% \mathrm{CO}_{2}$ at $37^{\circ} \mathrm{C}$.

154 We used the reporter gene assays to study the AhR transcriptional activity of FICZ compared 155 to TCDD and of the polyphenols and the mixture alone or co-exposing with TCDD/FICZ EC 50 
156 (more details about each experiment see section 3). The assays were carried out by following

157 the method described elsewhere (Scippo et al., 2004; Van der Heiden et al., 2009). Briefly,

158 after $24 \mathrm{~h}$ of seeding in white clear-bottomed 96 well microplates (Greiner) with about $90 \%$

159 confluence in the well, the cells were exposed to the tested compound/mixture for various

160 times in medium with $\operatorname{Trp}(\mathrm{MEM} \alpha, 10 \mathrm{mg} / \mathrm{L}$ L-Tryptophan) or without Trp (DMEM w/o Trp,

161 Biomol, Hamburg, Germany). Exposure was carried out with protection against direct light.

162 The culture medium was replaced by freshly prepared medium with the tested

163 compound/mixture. After exposure, the cells were washed with phosphate buffered saline

164 (Sigma Aldrich) and lysed by a solution containing Triton X100 (Sigma Aldrich). Light

165 production was triggered by adding luciferin (Promega, Wisconsin, USA) and ATP (Roche

166 Diagnostics, Rotkreuz, Switzerland) to the cell lysate and measured by a luminometer (ORION

167 II, Berthold Detection System, Pforzheim, Germany). Each experiment was repeated at least

168 three times independently in triplicate wells, together with a reference curve of TCDD/FICZ for

169 quality control. The final DMSO concentrations were $0.1 \%$ and $0.2 \%$, respectively for the

170 activation and the co-exposure experiments. Cytotoxicity was assessed by visual inspection

171 of cell morphology, attachment and density under microscope.

172

173 2.2.2. Calculations of fold induction (FI), relative response (RR), $E C_{50}$, and $\mathrm{IC}_{50}$

174 Luciferase activities in the reporter gene assays were recorded as relative light units (RLU).

175 The final results in the activation tests were presented as fold induction (FI). In the co-exposure

176 tests, the results were presented as relative response (RR). The FICZ/TCDD concentrations

177 for co-exposures were chosen at their respective $\mathrm{EC}_{50}$ to allow detection of further increase

178 or decrease of the AhR activation induced by the half-maximum effect of TCDD/FICZ with the

179 main focus on the inhibitory potency of the compound/mixture.

180

(1) $F I_{i(\text { activation })}=\frac{R L U_{i}}{R L U_{D M S O}}$

181

(2) $R R_{i(\text { co-exposure })}=\frac{R L U_{i}-R L U_{D M S O}}{R L U_{T C D D / F I C Z}-R L U_{D M S O}} \times 100$ 
$182 \mathrm{Fl}_{\mathrm{i}}$ in an activation test was the ratio (fold) between the response of the tested

183 compound/mixture (i) $\left(R L U_{i}\right)$ and the response of DMSO in the same plate (RLU $\left.U_{D M S O}\right)(E q$.

184 (1)). Meanwhile, $\mathrm{RR}_{\mathrm{i}}$ in a co-exposure test was the percentage (\%) of the response of the cells 185 to the tested compound/mixture (i) compared to the spike-in TCDD/FICZ EC 50 , subtracting the 186 baseline DMSO response (Eq. (2)). The non-linear regressions of four-parameter equations 187 for agonistic activation $\left(\mathrm{Fl}_{\mathrm{i}}\right)\left(\right.$ Eq. (3)) or antagonistic inhibition $\left(\mathrm{RR}_{\mathrm{i}}\right)(\mathrm{Eq}$. (4)) were used to fit 188 the dose-response curves (Graphpad PRISM software, version 7, San Diego, California, USA) 189 where $x$ was the concentration of the tested compound/mixture:

$$
\text { (3) } F I_{i(\text { activation })}=\text { bottom }+\frac{x^{\text {hillslope }}(\text { top }- \text { bottom })}{x^{\text {hillslope }}+E C_{50}{ }^{\text {hillslope }}}
$$

$$
\text { (4) } R R_{i(\text { co-exposure })}=\text { bottom }+\frac{\text { top }- \text { bottom }}{1+\frac{x_{\text {hillslope }}}{I C_{50} \text { hillslope }}}
$$

192 The corresponding $\mathrm{EC}_{50}$ and $\mathrm{IC}_{50}$ extrapolated by Graphpad PRISM from the full-dose response curves where available, were the concentrations of the tested compound/mixture exerting half their maximal effect (OECD, 2016). $\mathrm{FI}_{\max }$ and $\mathrm{RR}_{\max }$ were the maximum fold induction and the maximum relative response recorded within the tested concentration. Data from tests revealing cytotoxicity were excluded from the analyses.

\section{Results}

\subsection{Aryl hydrocarbon receptor transactivation by FICZ and TCDD}

200 The first experiment investigated the dose and time-dependent AhR transactivation by FICZ 201 and TCDD in rat DR-H4IIE and human DR-HepG2 cells, considering the role of endogenously 202 produced AhR ligands by using the standard medium containing $\operatorname{Trp}(\mathrm{MEM} \alpha)$ and the medium 203 without Trp (DMEM w/o Trp). In general, FICZ strongly activated AhR to a similar extent than 204 TCDD in both cell lines, however with different response patterns (Figure 1). A complete timecourse (2h to $24 \mathrm{~h}$ ) comparison is displayed in Figure $\mathrm{S} 1$, while $\mathrm{FI}_{\max }$ and $\mathrm{EC}_{50}$ values are in Figure S2. 
207 The response of DR-H4IIE cells to FICZ and TCDD was similar and influenced by the 208 presence of Trp in the culture medium. In MEM $\alpha$ with Trp, AhR activation was low $\left(F I_{\max } \cong 5\right.$

209 fold) after the cells' exposure to both TCDD and FICZ (Figure 1, A1 and B1) with a gradual

210 increase reaching $\mathrm{FI}_{\max }=12 \pm 0.2$ and $9 \pm 0.2$ fold, respectively, after $24 \mathrm{~h}$ (Figure 1, C1). In

211 DMEM w/o Trp, the cells' response to both FICZ and TCDD was 3-fold higher than in MEM $\alpha$,

212 e.g. after 6h exposure, $\mathrm{FI}_{\max }$ was about 15 fold (Figure 1, B1), although the dose-response

213 curves of the FICZ-induced activation started to degrade after 8h with much steeper curves

214 (Figure S1, D1 to G1).

216 In contrast, the AhR transactivation in DR-HepG2 cells mainly depended on the added agonist

217 (FICZ or TCDD). TCDD-induced human AhR activation in both culture media increased over

218 time and reached a maximum of 21 -fold induction after $24 \mathrm{~h}$ exposure (Figure S1, A2 to G2).

219 Meanwhile, the cells' response to FICZ increased during the first $4 \mathrm{~h}$ post-exposure (Figures

220 1, A2 and S1, A2 and B2), remained stable between 4h and 8h (Figures 1, B2 and S1, B2 to

221 D2), then decreased and completely vanished after 24h (Figures 1, C2 and S1, E2 to G2).

222 This quick decreasing response resulted in steeper curves and low $\mathrm{FI}_{\max }$ after 10h exposure, 223 indicating a fast metabolism of FICZ in DR-HepG2 cells. The cells were also dramatically more 224 sensitive to FICZ than to TCDD. For example, in DMEM w/o Trp, FICZ elicited $F I_{\max }=11$ fold 225 after $6 \mathrm{~h}$ exposure to $250 \mathrm{pM}$ FICZ, while at this time $10000 \mathrm{pM}$ of TCDD was required to 226 induce the same effect (Figure 1, B2), showing a 40-fold higher potency of FICZ compared to 227 TCDD. The corresponding FICZ EC 50 was $11 \pm 2.4 \mathrm{pM}, \sim 40$-fold lower than TCDD EC $\mathrm{E}_{50}=403$ $228 \pm 29$ pM (Figure S2, B2).

230 3.2. Aryl hydrocarbon receptor transcriptional activities of polyphenols and their 231 mixture

232 The seven individual polyphenols and their mixture were tested for AhR transcriptional 233 activities in rat DR-H4IIE and human DR-HepG2 cells in four different culture media conditions 
234 (DMEM w/o Trp, MEM $\alpha$, and DMEM w/o Trp added either FICZ or TCDD EC 50 ). Two exposure

235 times (4h and $8 \mathrm{~h}$ ) leading to relatively stable AhR responses to FICZ and TCDD (section 3.1)

236 were chosen for this experiment in order to avoid the complication of FICZ degradation through

237 the metabolic feedback loop. The spike-in TCDD $\mathrm{EC}_{50}$ for $4 \mathrm{~h}$ and $8 \mathrm{~h}$ exposure were,

238 respectively 85 pM and 15 pM in DR-H4IIE cells, and 650 pM and 250 pM in DR-HepG2 cells,

239 while for FICZ, $\mathrm{EC}_{50}$ were, respectively, $10 \mathrm{pM}$ and $30 \mathrm{pM}$ for both cell lines.

240

241 The polyphenols and their mixture induced no cytotoxicity in both cell lines, except curcumin at $50 \mu \mathrm{M}$ in DR-H4IIE cells, which was excluded from the data presented. In general, their activity increased from $4 \mathrm{~h}$ to $8 \mathrm{~h}$ post-exposure and vanished after $24 \mathrm{~h}$ (only tested in MEM $\alpha$ with Trp) in both cell lines, except chrysin which retained a moderate AhR activation in DRHepG2 cells, after $24 \mathrm{~h}$ exposure with $\mathrm{FI}_{\max }=3.4 \pm 0.5$ fold (data not shown). The doseresponse curves induced by the seven polyphenols and their mixture in the rat DR-H4IIE and human DR-HepG2 cells are shown in Figures S3 and S4, respectively.

In rat DR-H4IIE cells, in DMEM w/o Trp, the two isoflavones daidzein and genistein were shown to be AhR agonists. Daidzein exerted a $\mathrm{FI}_{\max }$ of $4.7 \pm 0.4$-fold, while the maximal fold induction for TCDD was 12-fold (Figure 2A). In the co-exposure experiment, daidzein surprisingly boosted the cell's responses to both FICZ and TCDD EC 50 , remarkably increasing the response to $\mathrm{FICZ} \mathrm{EC} 50$ up to $\mathrm{RR}_{\max }=744 \pm 63 \%$ and that to $\mathrm{TCDD} \mathrm{EC}_{50}$ up to $\mathrm{RR}_{\max }=$ $361 \pm 60 \%$ (Figure S3, A2). This resulted in a final $18 \pm 3$ and $9 \pm 2$-fold induction, respectively for FICZ and TCDD cotreatment, after the spike-in EC $_{50}$ reference subtraction (Figure 2A), showing an almost 4 and 2-fold increase compared to its respective agonistic activity alone.

257 Genistein stimulated the rat AhR activation in both media after 8h exposure, with $\mathrm{FI}_{\max }=5.9$ $258 \pm 1$ and $7.6 \pm 0.4$ fold, respectively, for medium without and with $\operatorname{Trp}$ (Figure 2B). Genistein also exerted an enhanced effect, but only when co-exposed to $\mathrm{FICZ} \mathrm{EC} \mathrm{C}_{50}\left(\mathrm{RR}_{\max }=782 \pm\right.$ 
154\%) (Figure S3, B2), which resulted in a final $24 \pm 1$-fold induction, showing a 4-fold increase

261 compared to its agonistic activity alone (Figure 2B).

263 This mutual enhancement resulting in a several fold increase suggests the presence of a 264 synergistic effect between the isoflavones and FICZ/TCDD in DR-H4IIE cells. In contrast, isoflavones displayed no significant activities in DR-HepG2 cells (Figure S4, A and B). Noticeably, in DR-HepG2 cells, daidzein, but not genistein, antagonized TCDD EC $\mathrm{E}_{50}\left(\mathrm{RR}_{\max }=\right.$ $\sim 40 \%$ ), but slightly increased the response to FICZ EC 50 (Figure S4, A2), indicating a selective AhR inhibitory effect of daidzein on TCDD induction.

For the other polyphenols, in the agonistic tests, the flavonol quercetin and both flavones (baicalin and chrysin) exerted strong human AhR agonistic effects in DR-HepG2 cells regardless of the presence of $\operatorname{Trp}$ in the culture medium with $\mathrm{FI}_{\max }=3.2 \pm 0.2,3.7 \pm 0.1$, and $5.2 \pm 0.2$ fold, respectively after $8 \mathrm{~h}$ exposure in DMEM w/o Trp (Figure $3 \mathrm{~A}$ ). A similar response pattern was observed when MEM $\alpha$ was used as exposure medium (Figure S4, C1 to E1). In DR-H4IIE cells, these polyphenols induced only a weak AhR activation of $\sim 2$ fold, at their highest concentrations, but only in MEM $\alpha$, (Figure S3, C1 to E1). In the same medium, resveratrol exerted relatively similar AhR agonistic responses in both cell lines (Figures S3,

278 G1 and S4, G1), similarly to the polyphenol mixture (Figures S3, H1 and S4, H1). However, in

279 DMEM w/o Trp after 8h exposure, they did not exert any agonistic effect in DR-HepG2 cells 280 (Figure 3A).

282 In co-exposure tests, only quercetin inhibited rat AhR activation by $T C D D E C_{50}$ with $R_{\max }=$ $33 \pm 8 \%$ after 4 h exposure (Figure S3, C2). Similar to the two isoflavones, resveratrol and the mixture seem to have a synergistic activity with FICZ EC 50 in DR-H4IIE cells after 8 h exposure (Figure S3, G2 and H2). In DR-HepG2 cells, curcumin was an AhR inhibitor which antagonized 
both TCDD and FICZ $\mathrm{EC}_{50}$, and even the DMSO baseline of the human AhR response,

287 regardless exposure time (Figures 3 and S4, F1 and F2).

289 However, quercetin was the strongest human AhR antagonist. Quercetin at $3 \mu \mathrm{M}$ totally

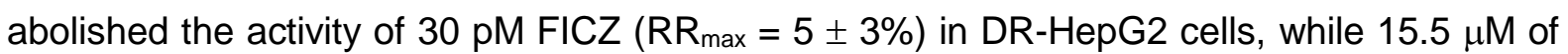
chrysin and $65 \mu \mathrm{M}$ of the mixture were needed for the same effect (Figure 3B). Baicalin and resveratrol caused the same antagonistic effects but to a lesser extent $\left(R R_{\max } \cong 50 \%\right.$ at 50 $\mu \mathrm{M})$ (Figure 3B). Both flavones did not affect the human AhR response to TCDD EC ${ }_{50}$, while quercetin antagonized strongly TCDD at $4 \mathrm{~h}$ and $8 \mathrm{~h}$ post-exposure, in presence of respectively $650 \mathrm{pM}$ and $250 \mathrm{pM}$ TCDD, showing a V-shaped response curve (Figures 3C and S4, C2). The lowest tested concentration of quercetin $(0.3 \mu \mathrm{M})$ already reduced by half TCDD $\mathrm{EC}_{50^{-}}$ induced AhR response of DR-HepG2 cells after $8 \mathrm{~h}$ exposure or completely after $4 \mathrm{~h}$, while 3 $\mu \mathrm{M}$ quercetin totally ablated the AhR activity induced by TCDD $\mathrm{EC}_{50}$ at both exposure times (Figures 3 C and S4, C2). The cells' response increased to around $R R_{\max }=50 \%$ at higher concentrations (30 $\mu \mathrm{M}$ and above), probably reflecting the agonistic activity of quercetin at these concentrations. Similarly to quercetin, only $6.3 \mu \mathrm{M}$ resveratrol strongly antagonized TCDD $\mathrm{EC}_{50}$ to $\mathrm{RR}_{\max }=25 \pm 7 \%$ after $8 \mathrm{~h}$ exposure in DR-HepG2 cells, but without a distinct V-shaped dose response curve (Figures $3 \mathrm{C}$ and S4, G2). Also, the polyphenol mixture strongly antagonized human AhR activation by TCDD $\mathrm{EC}_{50}$ with a dose-response curve similar to the one of quercetin (Figure $3 \mathrm{C}$ ). These results are summarized in Table S2.

3.3. Human aryl hydrocarbon receptor inhibitory activity of resveratrol, quercetin and the polyphenol mixture The TCDD inhibitory potentials in human DR-HepG2 cells of resveratrol, quercetin, and the

310 polyphenol mixture at low concentrations were further tested in DMEM w/o Trp for $8 \mathrm{~h}$

311 exposure. Figure 4A shows that both polyphenols and the mixture exhibited a strong inhibitory

312 effect on the human AhR activated by $650 \mathrm{pM}\left(\cong \mathrm{EC}_{70}\right) \mathrm{TCDD}$. While $5 \mu \mathrm{M}$ resveratrol inhibited 
313 the AhR activity induced by $650 \mathrm{pM}$ TCDD to $R R_{\max }=\sim 20 \%, 2.5 \mu \mathrm{M}$ quercetin or the mixture

314 at blood concentration $(\cong 2.5 \mu \mathrm{M})$ was able to totally abolish this activity. Their TCDD inhibitory

315 effects started at concentrations as low as 0.2 to $0.3 \mu \mathrm{M}$ (Figure $4 \mathrm{~A})$, and $\mathrm{IC}_{50}$ values were 1

$316 \pm 0.08,0.6 \pm 0.03$, and $0.8 \pm 0.06 \mu \mathrm{M}$, respectively, for resveratrol, quercetin, and the mixture.

317 Co-exposing the cells to these polyphenols or the mixture at the same concentration $(5 \mu \mathrm{M})$

318 with various concentrations of $\operatorname{TCDD}(0.15$ to $20 \mathrm{nM})$ (Figure $4 \mathrm{~B})$ revealed that resveratrol was

319 less efficient (a reduction of only $30 \%$ of TCDD $20 \mathrm{nM}$ induction was observed) than the

320 mixture and quercetin which blocked totally TCDD-induced AhR activation, even at the highest

321 TCDD concentration (20 nM).

322

323 The inhibitory effect on human AhR activation induced by TCDD EC $\mathrm{C}_{50}$ of the mixture at $8 \mathrm{~h}$ was

324 predicted using concentration addition (CA) and independent action (IA) models (Doan et al.,

325 2019) using the information of the four AhR antagonists namely, daidzein, quercetin,

326 curcumin, and resveratrol. The calculation not only allows the prediction of a realistic

327 combined effect, but also sheds light on the interactions among the polyphenols in the mixture

328 and their contributions for the mixture effect. Detailed calculations are presented in

329 supplementary information "Calculations of mixture effect and effect unit". Both the CA and IA

330 models predicted a dose-response curve which closely overlapped the experimentally

331 measured curve (Figure $4 \mathrm{C}$ ). The IA model predicted an $\mathrm{IC}_{50}=3.5 \mu \mathrm{M}$ close to $2.5 \mu \mathrm{M}$ of the

332 CA model, compared to a measured $0.8 \mu \mathrm{M} \mathrm{IC}_{50}$. Quercetin and resveratrol contributed for

$33356 \%$ and $39 \%$, respectively, to the mixture effect (Figure 4D).

\section{Discussion}

\subsection{Aryl hydrocarbon receptor responses to FICZ and TCDD}

337 This study is the first to show a direct and cross-species (rat and human) comparison of AhR

338 transactivation induced by endogenous FICZ and exogenous TCDD ligands in hepatoma

339 cells. We found that FICZ potency was similar on both rat and human AhR. However, FICZ 
340 was 40-fold more potent than TCDD in DR-HepG2 cells (Figure 1, S1 and S2). In a mouse

341 knock-in model where the endogenous mouse Ahr gene was entirely replaced with the human

$342 A H R$ gene, a reduction of TCDD-induced CYP1A family genes expression was observed,

343 although limited AHR protein accumulation might account for the attenuated responsiveness

344 of the model to TCDD (Moriguchi et al., 2003). This is in agreement with our previous finding 345 showing that the human AhR has a lower affinity for TCDD than the rat AhR (Doan et al., 346 2019). There is currently no data available for interspecies (rat and human) comparisons of

347 AhR responses to FICZ. Meanwhile, in an intraspecies comparison, the low affinity murine 348 isoform $\left(A h R^{d}\right)$ which is the result of an Alanine to Valine change at residue 375, showed a 4349 fold lower binding affinity for TCDD than the $A h R^{b}$ high affinity variant (Poland et al., 1994). 350 Nevertheless, both variants exhibited similar sensitivity to FICZ, and FICZ functioned similarly between the two mouse strains, exerting no differences in inducing T helper 17 immune cells

352 (Duarte et al., 2013). Additionally, the binding of different ligands (e.g. FICZ versus TCDD)

353 has been suggested to cause different AhR conformational changes, resulting in different 354 downstream consequences, e.g. in modulating the recruitment of various co-activators and 355 transcription factors (Denison et al., 2011). For example, a comparison of TCDD and FICZ in an in vivo mouse model for infection by the influenza virus revealed that they differentially affected various cell-specific AhR activators, most likely due to the different conformational changes that they induced (Wheeler et al., 2014).

360 In this study, depletion of Trp in the medium (DMEM w/o Trp) did not affect the AhR responses 361 in DR-HepG2 cells, but led to an almost 3-fold higher induction by both TCDD and FICZ after 362 4h to $10 \mathrm{~h}$ treatment in DR-H4IIE cells (Figures S1, B1 to E1 and 1, B1). A "pure" AhR 363 antagonist, GNF315 (Smith et al., 2011) at $10 \mu \mathrm{M}$ inhibited half (reduced 64\%) of the basal 364 luciferase signal of DR-H4IIE cells in MEM $\alpha$ after 6h treatment, but it had no significant effect 365 (reduced only 16\%) on the basal response in DR-HepG2 cells (data not shown). Thus, it is 366 likely that on top of the activities of the FICZ added, the rat AhR responded to the high level 
of basal AhR activation caused by endogenously produced ligands derived from Trp upon addition of the fresh medium. These ligands were unstable, as the difference in medium with and without Trp tended to vanish after $12 \mathrm{~h}$ treatment (Figure S1, F1 to G1).

In DR-HepG2 cells, AhR transactivation of both TCDD and FICZ was not affected by the presence of Trp in culture medium (Figure 1, A2 to C2). This could result from a lower conversion rate of $\operatorname{Trp}$ to $\mathrm{AhR}$ endogenous ligands, or conversion to different compounds. Moreover, we showed that FICZ clearance was high in this cell line. AhR ligands, except metabolically stable ligands, activate AhR to induce their own metabolism via the induction of AhR downstream regulated genes, and subsequently, their clearance from the body (Chiaro et al., 2007). FICZ, which is rapidly metabolized by CYP1 isoenzymes (Wincent et al., 2009), causes only transient AhR signaling, while TCDD induces persistent AhR responses. The different susceptibility to metabolic feedback loop likely determines the mode of action of

380 TCDD and FICZ (Duarte et al., 2013). Therefore, it appears that if FICZ clearance is blocked, such as by inhibiting the FICZ/AhR/CYP1A1 feedback loop, FICZ could also induce toxicity similar to that of TCDD, which have been observed in vivo in zebrafish embryos (Wincent et al., 2016). Thus, the metabolic feedback loop functions to prevent the toxicity of FICZ and possibly other labile AhR agonists (Brown et al., 2015; Wincent et al., 2016).

It is at present difficult to pinpoint the reason for the ligand-intrinsic differences in $A h R$ responses while different susceptibility to metabolism complicates the issue. However, the conservation of high FICZ potency in inducing AhR activation across different species and among different AhR isoforms suggests its physiological importance as an endogenous AhR ligand during evolution (Laub et al., 2010).

\subsection{Aryl hydrocarbon receptor responses to polyphenols and their mixture}

This study, for the first time, reports the species-specific AhR transcriptional activity in cells exposed to different polyphenols. Isoflavones (daidzein and genistein) were more active in the 
rat DR-H4IIE cells, while the flavonol quercetin, flavones (baicalin and chrysin) and curcumin

396 strongly affected the human AhR activity in DR-HepG2 cells. The stilbene resveratrol acted 397 equally on both cell lines. Although further investigations involving larger numbers of 398 polyphenols are necessary to evaluate the AhR species-responses of different polyphenol subclasses, the data are valuable for selecting polyphenols as active compounds specifically for human-aimed research and also raise a concern for traditional rodent-to-human extrapolation in risk assessments. It is important to stress here that these activities were only observed after short term exposure (4h or $8 \mathrm{~h}$ ), only chrysin maintained some of its activity after $24 \mathrm{~h}$.

The two isoflavones (daidzein and genistein) (Figure 2) exerted AhR agonistic effects in DRH4IIE cells and dramatically enhanced the cells' response in the presence of FICZ EC 50 (4fold higher than acting alone). Several previous studies revealed a stronger AhR induction due to the interference of polyphenols with the clearance of FICZ via the FICZ/AhR/CYP1A1 feedback loop (Choi and Kim, 2008; Froyen and Steinberg, 2016), however we chose to perform our experiments at $4 \mathrm{~h}$ and $8 \mathrm{~h}$ post-exposure, before FICZ degradation kicks in, therefore we most likely can rule out this mechanism for the observed synergistic effects. An enhanced induction was previously observed for the glucocorticoid receptor-mediated transcription due to sodium arsenite-induced chemical stress, or for progesterone or androgen stimulation by a combined treatment with forskolin (an activator of adenylate cyclase) and trichostatin A (an inhibitor of histone deacetylases) (Willemsen et al., 2005). Likewise, a rat AhR synergistic activity of genistein with 300 pM TCDD was observed previously that was explained by the various cellular functions of genistein (Van der Heiden et al., 2009). Thus, in our case, the synergistic effects of daidzein and genistein co-exposing with FICZ EC 50 were likely due to their activity on other pathway(s) which helped to enhance AhR transactivation more efficiently. Note that both daidzein and genistein are estrogenic compounds which are able to bind to the estrogen receptor (ER) (Tapiero et al., 2002), while cross-talk between AhR and ER has been well described (Matthews and Gustafsson, 2006; Safe and Wormke, 2003). 
423 Thus, it is possible that the synergistic activity of genistein and daidzein on the rat AhR could

424 result from the cross-talk between AhR and ER.

426 The flavonol quercetin and the two flavones (baicalin and chrysin) (Figure 3) exerted significant AhR agonistic and antagonistic effects in DR-HepG2 cells but not in DR-H4IIE cells.

428 Several mechanisms could explain the AhR agonistic activity of quercetin. Quercetin was reported as an inducer of CYP1A1 in human CaCo-2 cells, and the authors also showed the

430 interaction of quercetin with AhR using in silico tools (Jin et al., 2018). In addition, quercetin

431 was shown to significantly increase the AhR translocation by activating protein kinases $\mathrm{C}$ in

432 rats, facilitating the transcriptional activity of AhR in osteoblasts (Sharan et al., 2011).

433 Phosphorylation by e.g. protein kinases $\mathrm{C}$ is required for AhR activity in DNA binding and gene

434 transactivation and for the transformation of the unliganded AhR into a fully functionally active

435 AhR/ARNT heterodimer (Puga et al., 2009).

436

437 AhR antagonism of quercetin and chrysin at concentrations higher than $5 \mu \mathrm{M}$ was previously 438 shown for DR-HepG2 cells after 6h exposure (Van der Heiden et al., 2009). However, another 439 original finding of this study is the strong AhR antagonistic activity of quercetin but at very low 440 concentrations $(\leq 5 \mu \mathrm{M})$ in DR-HepG2 cells which were co-exposed to quercetin and 441 increasing concentrations of TCDD (Figure 4, A and B). One could suggest that quercetin is 442 a TCDD competitive antagonist, strongly competing to TCDD for binding sites on the human 443 AhR, similarly to alpha-naphthoflavone, a well-known AhR antagonist (Blank et al., 1987). 444 Quercetin was also found to induce AhRR (AhR repressor) mRNA expression in Caco- 2 cells, 445 thereby facilitating AhRR-dependent transrepression of AhR and inhibiting the BaP-AhR 446 activation via AhRR (Niestroy et al., 2011). However, there could be additional underlying 447 mechanism(s) for the strong antagonistic effect of quercetin in human DR-HepG2 cells, which 448 deserves further investigations. 
449 Resveratrol was an AhR agonist in both cell lines (Figures S3, G1 and S4, G1). It also 450 enhanced the response to FICZ of the rat AhR in the same manner as the two isoflavones 451 (Figure S3, G2). In addition, it was a strong AhR antagonist in DR-HepG2 cells, although less 452 potent than quercetin (Figures $3, \mathrm{~B}$ and $\mathrm{C}$ and $4, \mathrm{~A}$ and $\mathrm{B}$ ). Resveratrol was found to not exhibit 453 AhR agonistic or antagonistic activity in human breast cancer T47D or MCF-7 cells (Lee and 454 Safe, 2001). Instead, it inhibited CYP1A1 mRNA expression and CYP1A1-dependent activity 455 via an AhR-independent post-transcriptional pathway. It promoted the nuclear translocation 456 and/or DNA-binding activity of AhR, showing partial AhR-agonistic features. Meanwhile, it 457 reduced AhR-inducible gene expression without interfering with AhR-DRE binding, displaying its AhR-antagonistic effect when cells were co-exposed to TCDD. Also, CYP1A1 repression by resveratrol was shown to be dependent on ER since siRNA ER $\alpha$ was able to completely abolish the repressive effect of resveratrol on TCDD-inducible CYP1A1 mRNA accumulation in MCF-7 cells, but not in Caco-2 cells, indicating cell-specificity (Perdew et al., 2010).

We showed that curcumin (Figure 3) exerted an AhR antagonistic activity only in human DRHepG2 cells. In mouse Hepa-1c1c7 cells, curcumin was reported to accelerate the TCDDinduced AhR translocation, but inhibit the heterodimerization of AhR with ARNT by dosedependently inhibiting the TCDD-induced phosphorylation of both AhR and ARNT, thereby suppressing AhR activation (Nishiumi et al., 2007). Furthermore, oxidative stress was shown to be involved in mediating the curcumin-induced degradation of AhR and ARNT in human Hep3B and MCF-7 cells (Choi et al., 2008). These mechanisms might be less involved, or carried out by different cell components in the rat DR-H4IIE cells (Dere et al., 2011), thus explaining the nearly complete absence of AhR antagonism of curcumin in this study. To conclude, it seems that the effect of polyphenols on the AhR transcriptional activities is far more complicated since they rarely act as a direct AhR ligand only, but instead involve in several complex cellular pathways. 
476 The mixture of the seven polyphenols exerted an AhR agonistic activity in both cell lines.

477 Interestingly, similarly to quercetin, it also inhibited strongly the AhR activation induced by

478 TCDD at various concentrations in DR-HepG2 cells (Figure 4B). Both CA and IA models

479 resulted in an acceptable prediction of the antagonistic mixture effect (Figure 4C), indicating

480 that the activities of these polyphenols were additive in the mixture with similar or dissimilar

481 modes of action, in agreement with the conclusion of multiple intracellular targets of the

482 polyphenols.

483

484 Quercetin and resveratrol acted together, contributing to $95 \%$ of the AhR antagonistic mixture 485 effect, which was able to totally abolish the AhR activation of 650 pM TCDD in DR-HepG2 486 cells at a concentration of $2.5 \mu \mathrm{M}$ (Figure 4A). At this concentration, the mixture contained $487 \quad 0.33 \mu \mathrm{M}$ quercetin and $0.44 \mu \mathrm{M}$ resveratrol, corresponding to theoretical calculated blood levels (Table S1). According to literature, these concentrations could be realistic in human blood after dietary polyphenol ingestion. Quercetin is naturally found in onions, apples, broccoli, and berries (Li et al., 2016), while resveratrol is abundant in red grapes, red wine, peanuts, and ground nuts (Stervbo et al., 2007). Two main metabolites of quercetin, quercetin30-sulphate and quercetin-3-glucuronide, accumulated in human plasma with maximum concentration of $0.665 \mu \mathrm{M}$ and $0.351 \mu \mathrm{M}$ respectively after less than an hour after the ingestion of $270 \mathrm{~g}$ fried onions (Mullen et al., 2006). These two metabolites were found to display antitumor effects in MCF-7 cells, comparably to quercetin (Wu et al., 2018). Similarly, the blood concentration of resveratrol can peak at $2 \mu \mathrm{M}$ after an hour of single administration of an oral dose of $25 \mathrm{mg}$ of trans-resveratrol to healthy volunteers (Romero-Pérez et al., 1999).

In our previous study (Doan et al., 2019), we showed that a mixture of 29 persistent organic 500 pollutants, the total POP mixture prevalent in Scandinavian human blood, also caused an AhR antagonistic effect, which could be realistic. While this total POP mixture can cause a persisting AhR antagonism, the AhR antagonistic effects of quercetin, resveratrol, and the 
polyphenol mixture are only transient due to their fast metabolism. However, the health impact

504 of the human exposure to these multiple chemicals responsible for AhR antagonism should 505 be assessed.

\section{Conclusion}

508 We showed for the first time a side-by-side comparison of the effects of an endogenous AhR

509 ligand (FICZ) and exogenous ligand (TCDD) on two hepatoma cell lines from two different

510 organisms (rat and human). FICZ was 40 times more potent than TCDD in human DR-HepG2

511 cells and displayed similar potency in both cell lines, indicating its physiological importance as

512 an endogenous AhR ligand. Furthermore, we showed a significant effect of Trp depletion on

513 AhR activation in rat DR-H4IIE cells, but none in DR-HepG2 cells, probably due to the higher sensitivity of the former to the endogenously produced ligands from Trp, along with a faster

515 degradation of the ligand FICZ in the latter. The effect of seven polyphenols and their mixture

516 on AhR transcriptional activities alone and co-exposing with FICZ or TCDD was also

517 investigated. Both agonistic and antagonistic effects were observed, in line with the expected

518 complexity of a system where differential degradation of the tested compounds was certainly

519 playing a role, as well as interactions of the compounds, and their metabolites, with various

520 components of the cellular machinery. Antagonistic activity of quercetin, resveratrol, and the

521 mixture towards TCDD-induced human AhR activation was observed in this study at

522 nanomolar concentration, which is realistic in human exposure levels.

524 FICZ and other endogenous ligands together with polyphenols, in concert, regulate and maintain the vital physiological functions of AhR in balance. This balance can be disrupted by xenobiotic exposure or mis-applications of natural supplements but also can be used to treat diseases related to AhR disfunctions. Further studies are required to fully understand the

528 interference of these dietary polyphenols on the AhR-mediated activity of both endogenous 
and persistent xenobiotic AhR ligands in order to assess the health impact of their use as

530 drugs or food supplements.

531 Conflict of interest: The authors declare that there is no conflict of interest.

532 Acknowledgements: This project has received funding from the European Union's Horizon 2020 research and innovation program under the Marie Skłodowska-Curie grant agreement No. 722634. Muller M. is "Maître de Recherche" at the "Fonds National de la Recherche Scientifique". We thank the two anonymous reviewers for their insightful comments which helped to improve the manuscript.

\section{Reference}

Blank, J.A., Tucker, A.N., Sweatlock, J., Gasiewicz, T.A., Luster, M.I., 1987. alphaNaphthoflavone antagonism of 2,3,7,8-tetrachlorodibenzo-p-dioxin-induced murine lymphocyte ethoxyresorufin-O-deethylase activity and immunosuppression. Mol. Pharmacol. 32, 169-172.

Brown, D.R., Clark, B.W., Garner, L.V.T., Di Giulio, R.T., 2015. Zebrafish cardiotoxicity: the effects of CYP1A inhibition and AHR2 knockdown following exposure to weak aryl hydrocarbon receptor agonists. Environ. Sci. Pollut. Res. 22, 8329-8338. https://doi.org/10.1007/s11356-014-3969-2

Chiaro, C.R., Patel, R.D., Marcus, C.B., Perdew, G.H., 2007. Evidence for an aryl hydrocarbon receptor-mediated cytochrome P450 autoregulatory pathway. Mol. Pharmacol. 72, 1369-1379. https://doi.org/10.1124/mol.107.038968

Choi, E.J., Kim, T., 2008. Daidzein modulates induction of hepatic CYP1A1, 1B1, and AhR by 7,12-dimethylbenz[a]anthracene in mice. Arch. Pharm. Res. 31, 1115-1119. https://doi.org/10.1007/s12272-001-1277-3

Choi, H., Chun, Y.S., Shin, Y.J., Ye, S.K., Kim, M.S., Park, J.W., 2008. Curcumin attenuates cytochrome P450 induction in response to 2,3,7,8-tetrachlorodibenzo-p-dioxin by ROSdependently degrading AhR and ARNT. Cancer Sci. 99, 2518-2524. https://doi.org/10.1111/j.1349-7006.2008.00984.x 
Choi, S.H., Nishikawa, M., Sakoda, A., Sakai, Y., 2004. Feasibility of a simple doublelayered coculture system incorporating metabolic processes of the intestine and liver tissue: Application to the analysis of benzo[a]pyrene toxicity. Toxicol. Vitr. 18, 393-402. https://doi.org/10.1016/j.tiv.2003.09.010

Denison, M.S., Soshilov, A.A., He, G., Degroot, D.E., Zhao, B., 2011. Exactly the same but different: Promiscuity and diversity in the molecular mechanisms of action of the aryl hydrocarbon (dioxin) receptor. Toxicol. Sci. 124, 1-22. https://doi.org/10.1093/toxsci/kfr218

Dere, E., Lee, A.W., Burgoon, L.D., Zacharewski, T.R., 2011. Differences in TCDD-elicited gene expression profiles in human HepG2, mouse Hepa1c1c7 and rat H4IIE hepatoma cells. BMC Genomics 12, 193. https://doi.org/10.1186/1471-2164-12-193

Doan, T., Berntsen, H., Zimmer, K., Verhaegen, S., Ropstad, E., Connolly, L., Igout, A., Muller, M., Scippo, M., 2019. A realistic mixture of Persistent Organic Pollutants (POPs) inhibits the transactivation activity of the Aryl hydrocarbon Receptor (AhR) in vitro. Environ. Pollut. 254, 113098. https://doi.org/10.1016/j.envpol.2019.113098

Duarte, J.H., Di Meglio, P., Hirota, K., Ahlfors, H., Stockinger, B., 2013. Differential influences of the aryl hydrocarbon receptor on Th17 mediated responses in vitro and in vivo. PLoS One 8, e79819. https://doi.org/10.1371/journal.pone.0079819

Farmahin, R., Crump, D., Kennedy, S.W., 2014. Sensitivity of avian species to the aryl hydrocarbon receptor ligand 6-formylindolo [3,2-b] carbazole (FICZ). Chem. Biol. Interact. 221, 61-69. https://doi.org/https://doi.org/10.1016/j.cbi.2014.07.009

Fritsche, E., Schafer, C., Calles, C., Bernsmann, T., Bernshausen, T., Wurm, M., Hubenthal, U., Cline, J.E., Hajimiragha, H., Schroeder, P., Klotz, L.O., Rannug, A., Furst, P., Hanenberg, H., Abel, J., Krutmann, J., 2007. Lightening up the UV response by identification of the arylhydrocarbon receptor as a cytoplasmatic target for ultraviolet $B$ radiation. Proc. Natl. Acad. Sci. 104, 8851-8856. https://doi.org/10.1073/pnas.0701764104

Froyen, E.B., Steinberg, F.M., 2016. Genistein decreases basal hepatic cytochrome P450 

$1 \mathrm{~A} 1$ protein expression and activity in Swiss Webster mice. Nutr. Res. 36, 430-439. https://doi.org/10.1016/j.nutres.2016.01.001

Fujii-Kuriyama, Y., Kawajiri, K., 2010. Molecular mechanisms of the physiological functions of the aryl hydrocarbon (dioxin) receptor, a multifunctional regulator that senses and responds to environmental stimuli. Proc. Japan Acad. Ser. B Phys. Biol. Sci. 86, 40-53. https://doi.org/10.2183/pjab.86.40

Garrison, P.M., Tullis, K., Aarts, J.M.M.J.G., Brouwer, A., Giesy, J.P., Denison, M.S., 1996. Species-Specific Recombinant Cell Lines as Bioassay Systems for the Detection of 2,3,7,8-Tetrachlorodibenzo- p -dioxin-like Chemicals. Toxicol. Sci. 30, 194-203. https://doi.org/10.1093/toxsci/30.2.194

Hankinson, O., 1995. The Aryl Hydrocarbon Receptor Complex. Annu. Rev. Pharmacol. Toxicol. 35, 307-340. https://doi.org/10.1146/annurev.pa.35.040195.001515

Hardman, W.E., 2014. Diet components can suppress inflammation and reduce cancer risk. Nutr. Res. Pract. 8, 233-240. https://doi.org/10.4162/nrp.2014.8.3.233

Hubbard, T.D., Murray, I.A., Perdew, G.H., 2015. Indole and Tryptophan Metabolism: Endogenous and Dietary Routes to Ah Receptor Activation. Am. Soc. Pharmacol. Exp. Ther. 43, 1522-1535. https://doi.org/10.1124/dmd.115.064246

Jin, U.H., Park, H., Li, X., Davidson, L.A., Allred, C., Patil, B., Jayaprakasha, G., Orr, A.A., Mao, L., Chapkin, R.S., Jayaraman, A., Tamamis, P., Safe, S., 2018. StructureDependent Modulation of Aryl Hydrocarbon Receptor-Mediated Activities by Flavonoids. Toxicol. Sci. 164, 205-217. https://doi.org/10.1093/toxsci/kfy075 Jönsson, M.E., Franks, D.G., Woodin, B.R., Jenny, M.J., Garrick, R.A., Behrendt, L., Hahn, M.E., Stegeman, J.J., 2009. The tryptophan photoproduct 6-formylindolo[3,2b]carbazole (FICZ) binds multiple AHRs and induces multiple CYP1 genes via AHR2 in zebrafish. Chem. Biol. Interact. 181, 447-454. https://doi.org/10.1016/j.cbi.2009.07.003 Karunaweera, N., Raju, R., Gyengesi, E., Munch, G., 2015. Plant polyphenols as inhibitors of nf-Kb induced cytokine production-A potential anti-inflammatory treatment for alzheimer's disease? Front. Mol. Neurosci. 8, 1-5. 
613 Kawajiri, K., Fuji-KuriYama, Y., 2016. The aryl hydrocarbon receptor: a multifunctional

614 chemical sensor for host defense and homeostatic maintenance. Exp. Anim. 66, 75-89.

615 https://doi.org/10.1538/expanim.16-0092

616 Kim, I.S., Hwang, J.H., Hirano, M., Iwata, H., Kim, E.Y., 2016. In vitro and in silico evaluation

617 of transactivation potencies of avian AHR1 and AHR2 by endogenous ligands:

618 Implications for the physiological role of avian AHR2. Comp. Biochem. Physiol. Part C

619 Toxicol. Pharmacol. 187, 1-9. https://doi.org/https://doi.org/10.1016/j.cbpc.2016.03.011

620 Laub, L., Jones, B., Powell, W., 2010. Responsiveness of a Xenopus laevis cell line to the 621 aryl hydrocarbon receptor ligands 6-formylindolo[3,2- b]carbazole (FICZ) and 2,3,7,8-

622 tetrachlorodibenzo-p-dioxin (TCDD). Chem Biol Interact 183, 202-211.

$623 \quad$ https://doi.org/10.1038/jid.2014.371

624 Lee, J.E., Safe, S., 2001. Involvement of a post-transcriptional mechanism in the inhibition of 625 CYP1A1 expression by resveratrol in breast cancer cells. Biochem. Pharmacol. 62, 626 1113-1124. https://doi.org/10.1016/S0006-2952(01)00763-8

627 Li, Y., Yao, J., Han, C., Yang, J., Chaudhry, M.T., Wang, S., Liu, H., Yin, Y., 2016.

628 Quercetin, inflammation and immunity. Nutrients 8, 1-14.

629 https://doi.org/10.3390/nu8030167

630 Marlowe, J.L., Puga, A., 2005. Aryl hydrocarbon receptor, cell cycle regulation, toxicity, and 631 tumorigenesis. J. Cell. Biochem. 96, 1174-1184. https://doi.org/10.1002/jcb.20656

632 Matthews, J., Gustafsson, J.-Å., 2006. Estrogen receptor and aryl hydrocarbon receptor 633 signaling pathways. Nucl. Recept. Signal. 4. https://doi.org/10.1621/nrs.04016

634 Middleton, E., Kandaswami, C., Theoharides, T.C., 2000. The effects of plant flavonoids on 635 mammalian cells: Implications for inflammation, heart disease, and cancer. Pharmacol. $636 \quad$ Rev. 52, 673-751.

637 Moriguchi, T., Motohashi, H., Hosoya, T., Nakajima, O., Takahashi, S., Ohsako, S., Aoki, Y., 638 Nishimura, N., Tohyama, C., Fujii-Kuriyama, Y., Yamamoto, M., 2003. Distinct 639 response to dioxin in an arylhydrocarbon receptor (AHR)-humanized mouse. Proc. Natl. 
Mullen, W., Edwards, C.A., Crozier, A., 2006. Absorption, excretion and metabolite profiling of methyl-, glucuronyl-, glucosyl- and sulpho-conjugates of quercetin in human plasma and urine after ingestion of onions. Br. J. Nutr. 96, 107. https://doi.org/10.1079/bjn20061809

Niestroy, J., Barbara, A., Herbst, K., Rode, S., van Liempt, M., Roos, P.H., 2011. Single and concerted effects of benzo[a]pyrene and flavonoids on the AhR and Nrf2-pathway in the human colon carcinoma cell line Caco-2. Toxicol. Vitr. 25, 671-683. https://doi.org/https://doi.org/10.1016/j.tiv.2011.01.008

Nishiumi, S., Yoshida, K. ichi, Ashida, H., 2007. Curcumin suppresses the transformation of an aryl hydrocarbon receptor through its phosphorylation. Arch. Biochem. Biophys. 466, 267-273. https://doi.org/10.1016/j.abb.2007.08.007

O’Brien, P.J., 2014. High-content analysis in toxicology: Screening substances for human toxicity potential, elucidating subcellular mechanisms and in vivo use as translational safety biomarkers. Basic Clin. Pharmacol. Toxicol. 115, 4-17. https://doi.org/10.1111/bcpt.12227

OECD, 2016. Test No. 455: Performance-Based Test Guideline for Stably Transfected Transactivation In Vitro Assays to Detect Estrogen Receptor Agonists and Antagonists. https://doi.org/10.1787/20745788

Perdew, G.H., Hollingshead, B.D., DiNatale, B.C., Morales, J.L., Labrecque, M.P., Takhar, M.K., Tam, K.J., Beischlag, T. V., 2010. Estrogen receptor expression is required for low-dose resveratrol-mediated repression of aryl hydrocarbon receptor activity. J. Pharmacol. Exp. Ther. 335, 273-283. https://doi.org/10.1124/jpet.110.170654

Poland, A., Palen, D., Glover, E., 1994. Analysis of the four alleles of the murine aryl hydrocarbon receptor. Mol. Pharmacol. 46, 915-921.

Puga, A., Ma, C., Marlowe, J.L., 2009. The aryl hydrocarbon receptor cross-talks with multiple signal transduction pathways. Biochem Pharmacol 77, 713-722. https://doi.org/doi:10.1016/j.bcp.2008.08.031 
668 Quideau, S., Deffieux, D., Douat-Casassus, C., Pouységu, L., 2011. Plant Polyphenols:

669 Chemical Properties, Biological Activities, and Synthesis. Angew. Chemie Int. Ed. 50,

$670 \quad$ 586-621. https://doi.org/10.1002/anie.201000044

671 Rannug, A., Rannug, U., 2018. The tryptophan derivative 6-formylindolo[3,2-b]carbazole,

672 FICZ, a dynamic mediator of endogenous aryl hydrocarbon receptor signaling,

673 balances cell growth and differentiation. Crit. Rev. Toxicol. 48, 555-574.

$674 \quad$ https://doi.org/10.1080/10408444.2018.1493086

675 Rannug, A., Rannug, U., Rosenkranz, H., Winqvist, L., Westerholm, R., Agurell, E.,

676 Grafstrom, A., 1987. Certain photooxidized derivatives of tryptophan bind with very high

677 affinity to the Ah receptor and are likely to be endogenous signal substances. J. Biol.

$678 \quad$ Chem. 262, 15-427.

679 Romero-Pérez, A.I., Ibern-Gómez, M., Lamuela-Raventós, R.M., De La Torre-Boronat, M.C., 680 1999. Piceid, the major resveratrol derivative in grape juices. J. Agric. Food Chem. 47, 1533-1536. https://doi.org/10.1021/jf981024g

682 Safe, S., Wormke, M., 2003. Inhibitory aryl hydrocarbon receptor-estrogen receptor a cross683 talk and mechanisms of action. Chem. Res. Toxicol. 16, 807-816.

$684 \quad$ https://doi.org/10.1021/tx034036r

685 Scippo, M.L., Eppe, G., De Pauw, E., Maghuin-Rogister, G., 2004. DR-CALUX® screening 686 of food samples: Evaluation of the quantitative approach to measure dioxin, furans and 687 dioxin-like PCBs. Talanta 63, 1193-1202. https://doi.org/10.1016/j.talanta.2004.05.037

688 Sharan, K., Mishra, J.S., Swarnkar, G., Siddiqui, J.A., Khan, K., Kumari, R., Rawat, P., 689 Maurya, R., Sanyal, S., Chattopadhyay, N., 2011. A novel quercetin analogue from a 690 medicinal plant promotes peak bone mass achievement and bone healing after injury 691 and exerts an anabolic effect on osteoporotic bone: The role of aryl hydrocarbon 692 receptor as a mediator of osteogenic action. J. Bone Miner. Res. 26, 2096-2111. $693 \quad$ https://doi.org/10.1002/jbmr.434

694 Smirnova, A., Wincent, E., Vikström Bergander, L., Alsberg, T., Bergman, J., Rannug, A., 695 Rannug, U., 2016. Evidence for New Light-Independent Pathways for Generation of the 

https://doi.org/10.1021/acs.chemrestox.5b00416

698 Smith, K.J., Murray, I.A., Tanos, R., Tellew, J., Boitano, A.E., Bisson, W.H., Kolluri, S.K., 699 Cooke, M.P., Perdew, G.H., 2011. Identification of a high-affinity ligand that exhibits $700 \quad$ complete aryl hydrocarbon receptor antagonism. J. Pharmacol. Exp. Ther. 338, 318327. https://doi.org/10.1124/jpet.110.178392

Stejskalova, L., Dvorak, Z., Pavek, P., 2011. Endogenous and exogenous ligands of aryl hydrocarbon receptor: current state of art. Curr Drug Metab 12, 198-212. https://doi.org/BSP/CDM/E-Pub/000128 [pii]

Stervbo, U., Vang, O., Bonnesen, C., 2007. A review of the content of the putative chemopreventive phytoalexin resveratrol in red wine. Food Chem. 101, 449-457. https://doi.org/https://doi.org/10.1016/j.foodchem.2006.01.047

Tapiero, H., Nguyen Ba, G., Tew, K.D., 2002. Estrogens and environmental estrogens. Biomed. Pharmacother. 56, 36-44. https://doi.org/https://doi.org/10.1016/S07533322(01)00155-X

Van der Heiden, E., Bechoux, N., Muller, M., Sergent, T., Schneider, Y.J., Larondelle, Y., Maghuin-Rogister, G., Scippo, M.L., 2009. Food flavonoid aryl hydrocarbon receptormediated agonistic/antagonistic/synergic activities in human and rat reporter gene assays. Anal. Chim. Acta 637, 337-345. https://doi.org/10.1016/j.aca.2008.09.054

Wall, R.J., Fernandes, A., Rose, M., Bell, D.R., Mellor, I.R., 2015. Characterisation of chlorinated, brominated and mixed halogenated dioxins, furans and biphenyls as potent and as partial agonists of the Aryl hydrocarbon receptor. Environ. Int. 76, 49-56. https://doi.org/10.1016/j.envint.2014.12.002

Wheeler, J.L.H., Martin, K.C., Resseguie, E., Paige Lawrence, B., 2014. Differential consequences of two distinct AhR ligands on innate and adaptive immune responses to influenza A virus. Toxicol. Sci. 137, 324-334. https://doi.org/10.1093/toxsci/kft255 
responsive bioassays. Anal. Bioanal. Chem. 382, 894-905. https://doi.org/10.1007/s00216-005-3253-x

Williamson, G., 2017. The role of polyphenols in modern nutrition. Nutr. Bull. 42, 226-235. https://doi.org/10.1111/nbu.12278

Wincent, E., Amini, N., Luecke, S., Glatt, H., Bergman, J., Crescenzi, C., Rannug, A., Rannug, U., 2009. The suggested physiologic aryl hydrocarbon receptor activator and cytochrome P4501 substrate 6-formylindolo[3,2-b]carbazole is present in humans. J. Biol. Chem. 284, 2690-2696. https://doi.org/10.1074/jbc.M808321200

Wincent, E., Kubota, A., Timme-Laragy, A., Jönsson, M.E., Hahn, M.E., Stegeman, J.J., 2016. Biological effects of 6-formylindolo[3,2-b]carbazole (FICZ) in vivo are enhanced by loss of CYP1A function in an Ahr2-dependent manner. Biochem. Pharmacol. 110111, 117-129. https://doi.org/10.1016/j.bcp.2016.04.012

Wright, E.J., Pereira De Castro, K., Joshi, A.D., Elferink, C.J., 2017. Canonical and noncanonical aryl hydrocarbon receptor signaling pathways. Curr. Opin. Toxicol. 2, 87-92. https://doi.org/10.1016/j.cotox.2017.01.001

Wu, Q., Needs, P.W., Lu, Y., Kroon, P.A., Ren, D., Yang, X., 2018. Different antitumor effects of quercetin, quercetin-3'-sulfate and quercetin-3-glucuronide in human breast cancer MCF-7 cells. Food Funct. 9, 1736-1746. https://doi.org/10.1039/C7FO01964E

Xue, Z., Li, D., Yu, W., Zhang, Q., Hou, X., He, Y., Kou, X., 2017. Mechanisms and therapeutic prospects of polyphenols as aryl hydrocarbon receptor modulators. Food Funct. 8, 1414-1437. https://doi.org/10.1039/c6fo01810f 


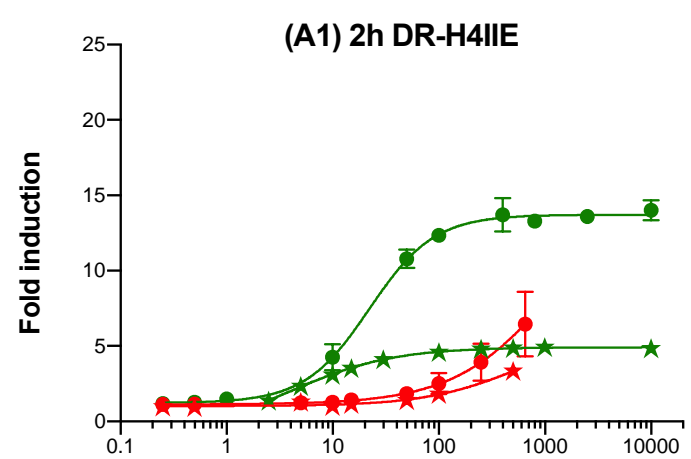

$\mathrm{pM}$

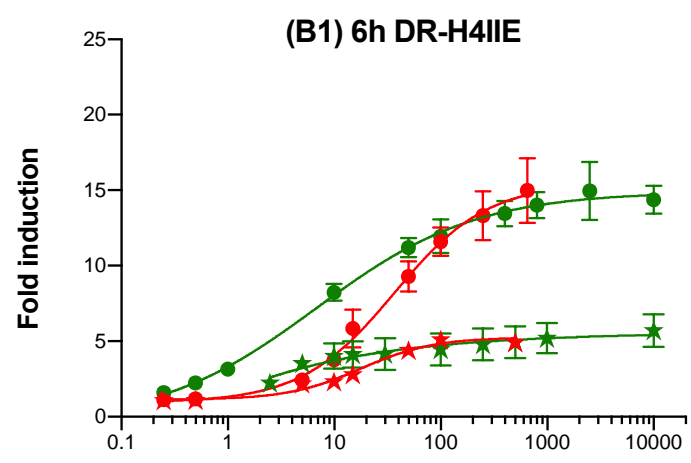

$\mathrm{pM}$

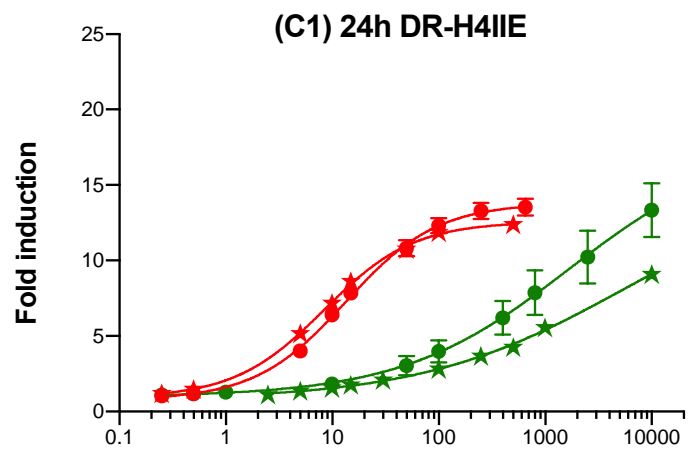

$\mathrm{pM}$

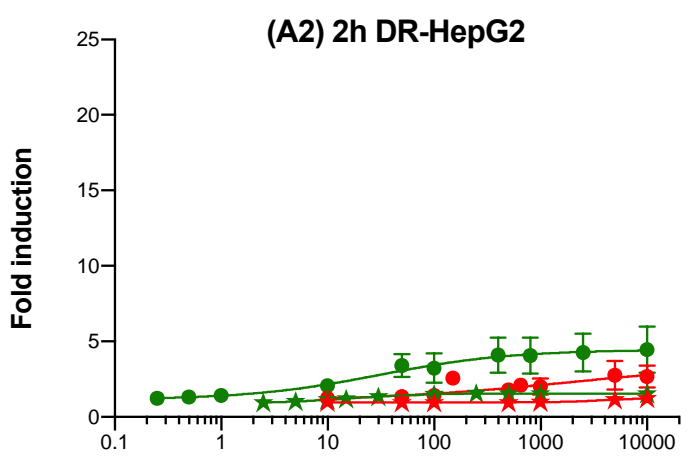

$\mathrm{pM}$

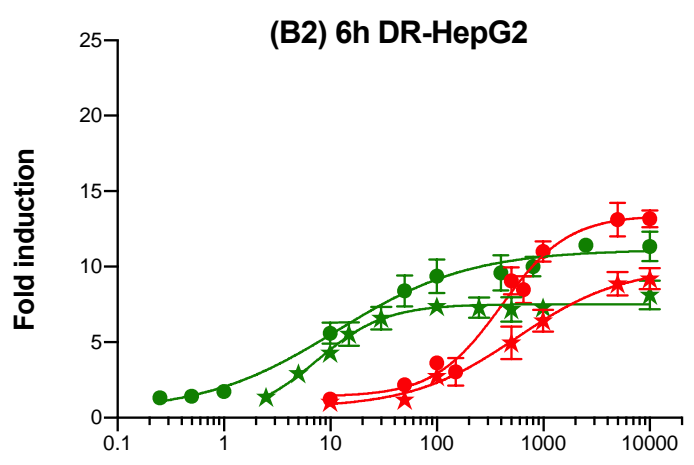

pM

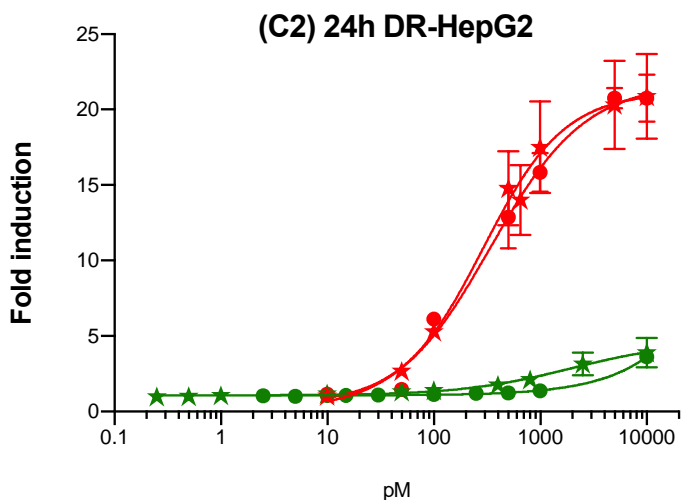

749

750 Figure 1. Dose response curves of rat DR-H4IIE and human DR-HepG2 cells exposed to

751 TCDD or FICZ in culture medium with (MEM $\alpha)$ and without Trp (DMEM w/o Trp) at 2h (A), $6 \mathrm{~h}$

752 (B) and 24h (C) post-exposure (Mean $\pm S D, n=3$ ). 

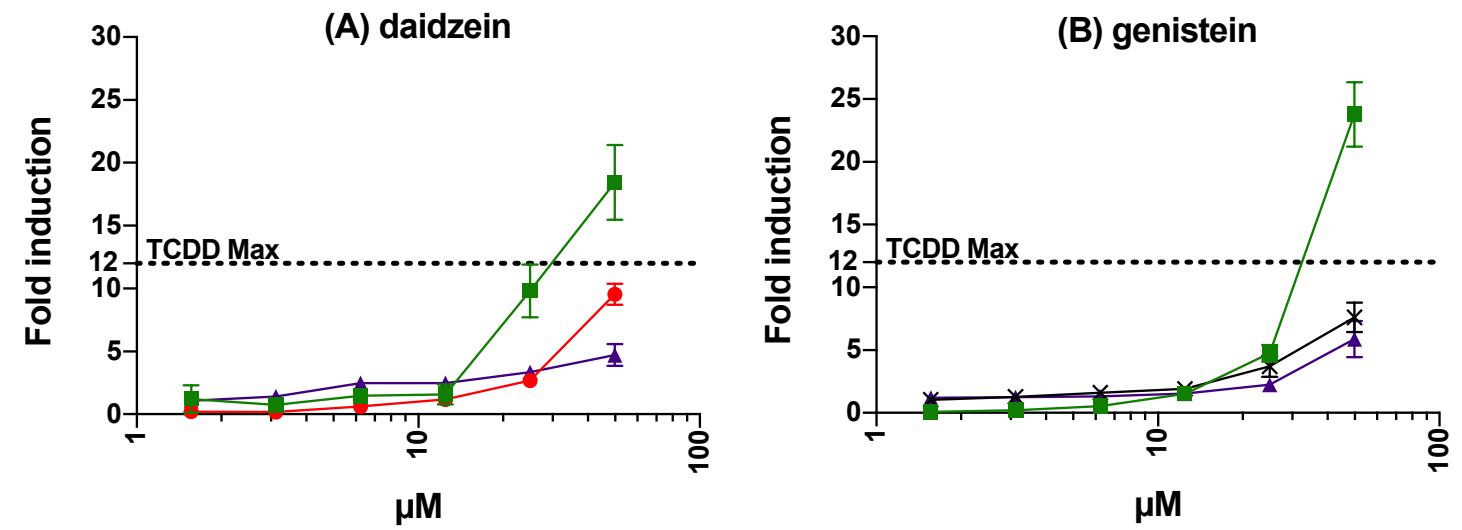

$\rightarrow$ DMEM w/o Trp $\rightarrow$ DMEM w/o Trp $+30 \mathrm{pM} \mathrm{FICZ}$

* MEMa

-- DMEM w/o Trp + 15 pM TCDD

755 Figure 2. Dose response curves of rat DR-H4IIE cells responding to (A) daidzein or (B)

756 genistein in medium with $\operatorname{Trp}(\mathrm{MEM} \alpha)$, without Trp (DMEM w/o Trp) or cotreated with FICZ or

757 TCDD $E_{50}$ in DMEM w/o Trp for 8h induction (Mean \pm SD, $n=3$ ). TCDD Max: maximum 758 response of TCDD at the same condition. 
(A) DMEM w/o Trp

759

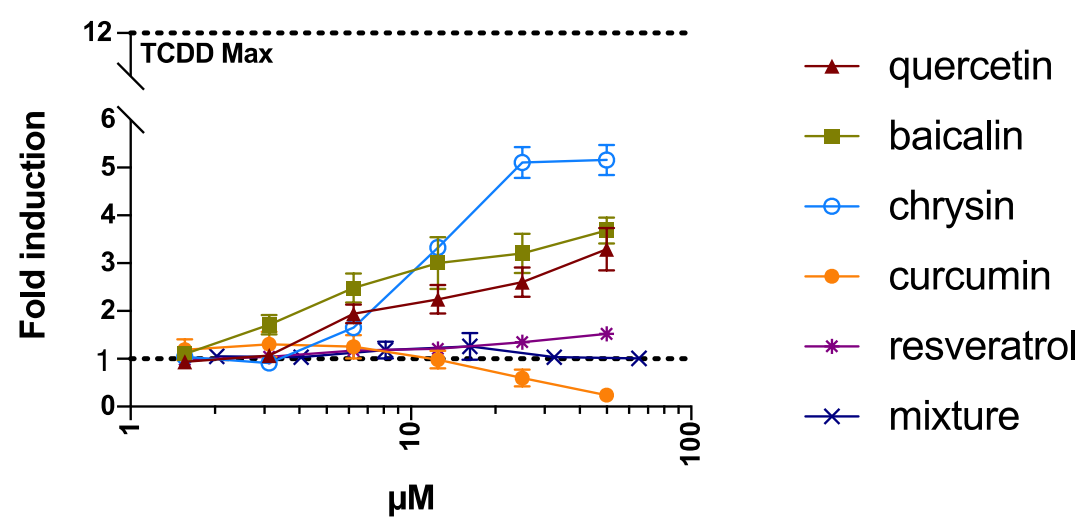

(B) DMEM w/o Trp + 30 pM FICZ

(C) DMEM w/o Trp + 250 pM TCDD

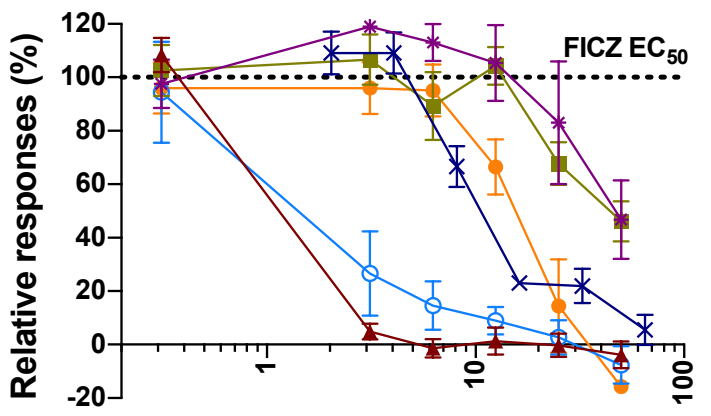

$\mu \mathrm{M}$

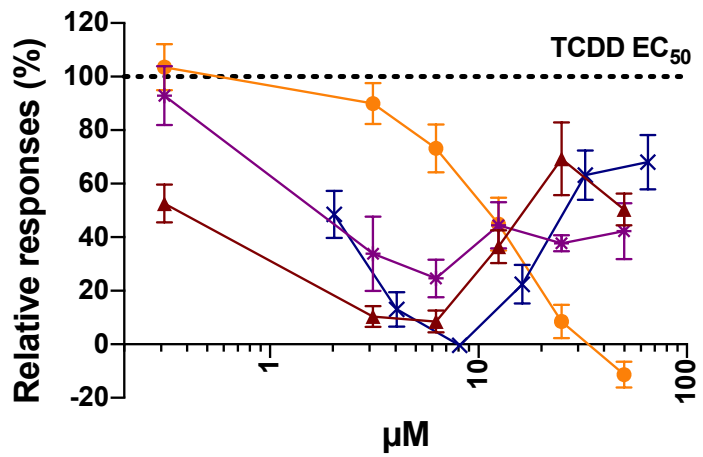

$\mu \mathrm{M}$

Figure 3. Dose response curves of human DR-HepG2 cells responding to quercetin, baicalin,

762 chrysin, curcumin, resveratrol, or the polyphenol mixture in (A) medium without Trp (DMEM

763 w/o Trp) or cotreated with (B) FICZ EC 50 or (C) TCDD EC E0 $_{50}$ in DMEM w/o Trp for 8h induction

764 (Mean $\pm S D, n=3$ ). TCDD Max: maximum response of TCDD at the same condition. 


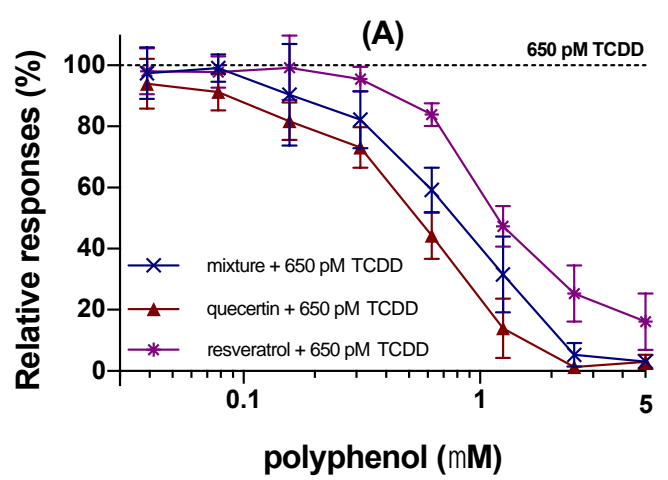

(C)

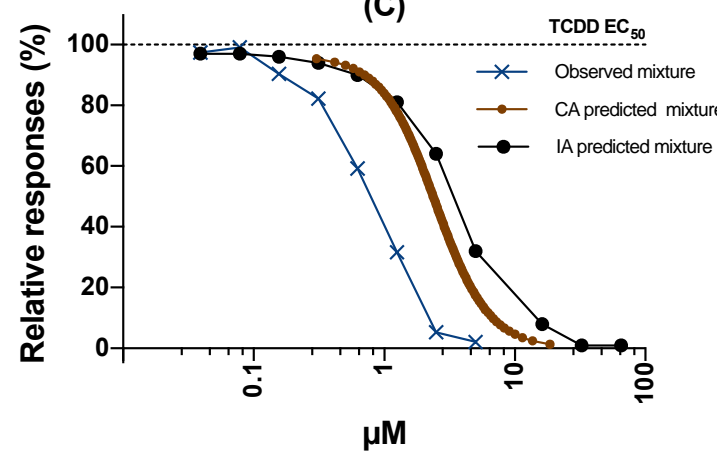

(B)

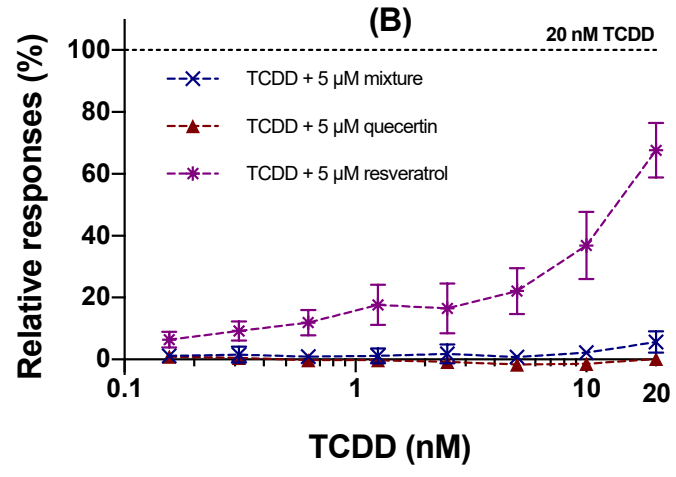

(D)

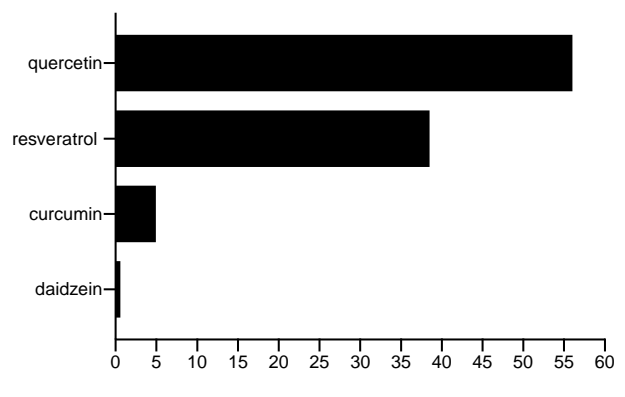

$\%$

Figure 4: Dose response curves of DR-HepG2 cells responding to $(A)$ the mixture, quercetin,

768 and resveratrol co-exposed with $650 \mathrm{pM} \mathrm{TCDD}$ and (B) various TCDD concentrations co-

769 exposed with $5 \mu \mathrm{M}$ of these polyphenols. (C) The predicted and measured dose response

770 curves of the mixture after 8h induction. (D) Distribution of effect units of the four active AhR

771 antagonists in the mixture. CA: concentration addition. IA: independent action. 